\title{
Spondyloepiphyseal Dysplasia Congenita in a painting of Vicente López y Portaña (1825)
}

\author{
C. M. Oranges ${ }^{1}$ M. Tremp ${ }^{1} \cdot$ A. Kaempfen ${ }^{1} \cdot$ D. J. Schaefer ${ }^{1}$
}

Received: 26 October 2015 / Accepted: 30 November 2015 / Published online: 15 December 2015

(C) Italian Society of Endocrinology (SIE) 2015

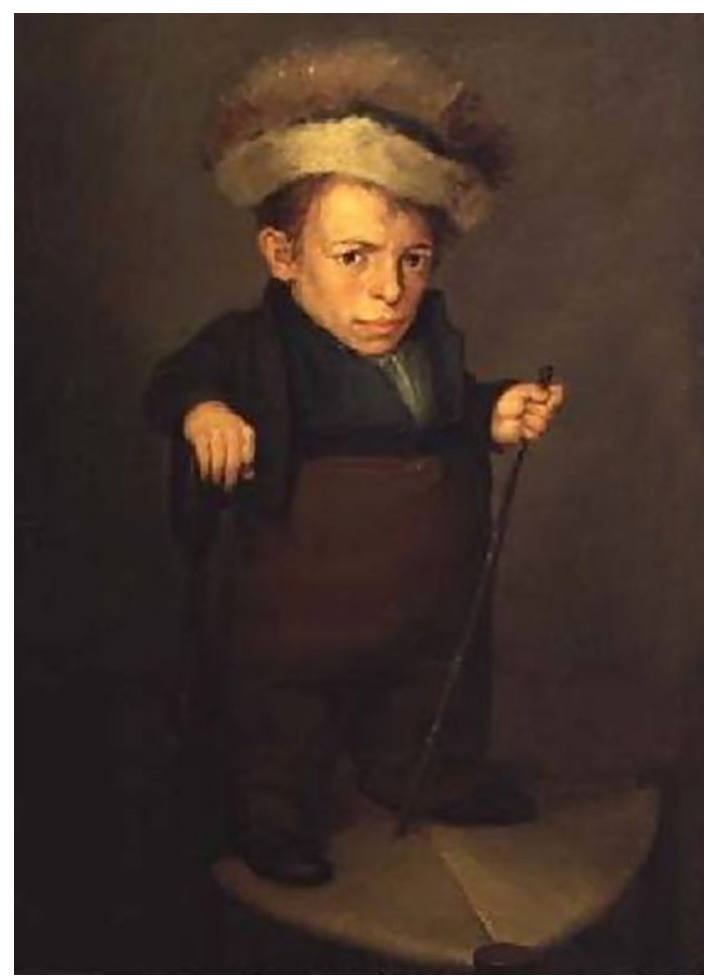

The painting entitled "Aragonese Dwarf" is an oil on canvas realized in 1825 by the Spanish neoclassical painter Vicente López y Portaña (Valencia, 1772-Madrid, 1850).

C. M. Oranges

studioranges22@gmail.com

D. J. Schaefer

dirk.schaefer@usb.ch

1 Department of Plastic, Reconstructive, Aesthetic and Hand Surgery, Basel University Hospital, Spitalstrasse 21, 4031 Basel, Switzerland
The subject of the picture presents with disproportionate short-trunk dwarfing condition, relative macrocephaly and flat face. The limbs are short with hands and feet average-sized.

These phenotypic aspects lead to the diagnosis of Spondyloepiphyseal Dysplasia Congenita (SEDC), a rare inherited autosomal dominant disorder, with a prevalence of approximately 1 per 100,000 live births [1]. The disease, which belongs to the group of type II collagenopathy, results from mutations in type II collagen gene (COL2A1, MIM 183900) [2].

The picture, exposed at Harvard Fogg Art Museum, Cambridge, Massachusetts, can be considered an effective artistic representation of the pathology.

\section{Compliance with ethical standards}

Conflict of interest The authors declare that they have no conflict of interest.

Ethical approval This paper does not contain any studies with human participants or animals performed by any of the authors.

Informed consent No informed consent

\section{References}

1. Offiah AC (2015) Skeletal dysplasias: an overview. Endocr Dev 28:259-276. doi:10.1159/000381051

2. Bonafe L, Cormier-Daire V, Hall C et al (2015) Nosology and classification of genetic skeletal disorders: 2015 revision. Am J Med Genet A. doi:10.1002/ajmg.a.37365 